\title{
Chapter 11 \\ Intertwinement of Rationality and Emotions in Mathematics Teaching: A Case Study
}

\author{
Marina De Simone
}

\begin{abstract}
In this paper, I will analyse a mathematics teacher's classroom actions using a theoretical framework that tries to bring together the cognitive and affective dimensions, often considered separately. In particular, I will concentrate on the relation between the actions of a teacher, Carla, in her grade nine classroom and her reasons for those actions, through a combined analysis of the language and the emotional elements that accompany her speech. To carry out this analysis, I will combine Habermas' theory of rationality and the concept of emotional orientation developed by Brown and Reid within the research in mathematics related affect. From a methodological point of view, I interviewed the teacher to detect some of her expectations for her teaching decision. To confirm that these expectations I identified a priori are those that actually guide Carla during her teaching practice, I also analysed her classroom activity focusing mainly on her "emotional indicators", namely gestures, facial expressions, emphasis of the words, repetition, and so on. Finally, I examined the lessons more carefully in order to identify intertwinement between the teacher's rationality and emotions.
\end{abstract}

Keywords Mathematics teacher $\cdot$ Decision-making $\cdot$ Rationality $\cdot$ Emotional orientation $\cdot$ Linear equations

\subsection{Introduction}

This paper draws on my earlier research, on how cognition and affect are intertwined in a mathematics teacher's decision-making processes (De Simone, 2015). Decisionmaking is a characteristic feature of teaching since teachers are constantly making decisions within the classroom. Indeed, many authors have recognized that decisionmaking has a crucial role in the work of mathematics teachers. For example, Bishop

\footnotetext{
M. De Simone (凶)

Faculté de Psychologie et des Sciences de l'Education, Université de Genève,

Bd du Pont d'Arve, 40, 1211 Geneva, Switzerland

e-mail: marina.desimone@unige.ch 
(1976) considers decision-making as the activity that is " ... at the heart of the teaching process" (p. 42).

The rationality and emotions of the mathematics teacher are considered in the research described in this chapter as two sides of the same coin. Thus I attempt to go beyond the Cartesian dualism between the res extensa and the res cogitans towards a holistic view of both body and mind. Indeed, the neuroscientist Damasio (1994) speaks in terms of "Descartes' error" in relation to "the abyssal separation between body and mind [...]; the suggestion that reasoning, and moral judgment, and the suffering that comes from physical pain or emotional upheaval might exist separately from the body." (pp. 249-250) Damasio's work supports the view that accounting only for the rationality of the teacher would not allow one to make a complete-or even a valid - analysis of the process involved in teachers' decision-making.

In the first section of the paper, I will explain why and how the original research problem evolved. In particular, I will introduce the theoretical lens I chose for analysing the rationality of the teacher, which started with the work of Habermas. I will then continue to discuss some critical debates around Habermas' approach. This critique enabled me to formulate a kind of rationality in which the affective dimension of decision-making is emphasized, drawing on recent research in mathematics related affect. After describing the methodological choices I made in my research, I will move on to a case study analysis of one grade nine mathematics teacher, Carla whose decision-making will be shown to intertwine both rationality and emotions. In the light of this case study I will then discuss how and why the adopted theoretical framework allows an analysis of teacher behaviour in detail.

\subsection{Theoretical Framework}

Originally, my research aim was to study rationality in the teacher decision-making processes, in the context of discursive activity of explaining linear equations. I set my research in the framework of Habermas' (1998) philosophical theory of rationality, re-elaborated and adjusted to mathematics education (Boero, Douek, Morselli, \& Pedemonte, 2010; Boero \& Planas, 2014). In particular, Habermas speaks of discursive rationality of a rational being involved in a discursive activity. First of all, he defines a rational being as a human being who "can give account for his orientation toward validity claims" (Habermas, 1998, p. 310). Then, he explains that the discursive rationality has three different roots: the knowledge, the action, and the speech or, in a different manner, the knowing, the acting, and the speaking.

At this point, it already became evident that the discursive rationality of the teacher is deeply connected to her decision-making space, because a rational being involved in a discursive activity is a decisional agent. Each root of the discursive rationality is connected to a particular type of rationality: the knowledge is connected to the epistemic rationality, the action is connected to the teleological rationality, and the speech is connected to the communicative rationality. The structure of discourse determines an intertwinement of the knowledge, the action, and the speech "by 
bringing together" the three types of rationality (Habermas, 1998, p. 309). These three types of rationality are inseparable, since a rational being acts in a specific manner to achieve a goal, on the basis of a specific knowledge, and communicating in a precise way. Hence, the three types of rationality are always present in the discursive activity; the only thing an external observer can see is the prevalence of one of the three types over the others. For example, it could be that, in a specific moment of the discursive activity of the teacher, only the epistemic rationality is "visible" and there is no sign of the teleological one.

As Habermas affirms, the epistemic rationality is connected with a specific idea of knowledge that is not in a trivial sense a collection of facts. Habermas explains that, "in order to know something in an explicit sense, it is not, of course, sufficient merely to be familiar with facts that could be represented in true judgements. We know facts and have a knowledge of them at our disposal only when we simultaneously know why the corresponding judgments are true. Otherwise we speak of intuitive or implicit knowledge — of a "practical' knowledge of how one does something" (Habermas, 1998, pp. 311-312). Epistemic rationality requires that we can also give an account of the justification for the knowledge at play. Conversely, someone is irrational when she puts forward her beliefs in a dogmatic way, "clinging to them although she sees that she cannot justify them" (Habermas, 1998, p. 312). By its very nature, the epistemic rationality is deeply entwined with the action and the use of language. For this reason, epistemic rationality is not a self-supporting structure, but it is always combined with action and discourse.

Furthermore, Habermas (1998) speaks of teleological rationality when "the actor has achieved this result on the basis of the deliberately selected and implemented means" (p. 313). Developing this perspective, Habermas affirms that a successful actor has acted rationally when, first, he knows and he is conscious of why he was successful, and then "this knowledge motivates the actor (at least in part) in such a way that he carries out his action for reasons that can at the same time explain its possible success" (p. 314).

Finally, he states that the communicative rationality "is expressed in the unifying force of speech oriented toward reaching understanding" (Habermas, 1998, p. 315). The communicative use of linguistic expressions not only gives a "life" to the intentions of the subject, but also represents the actually occurring communicative state and, furthermore, establishes interpersonal relations with a second person. Once again, the communicative rationality is strictly connected to the epistemic and the teleological ones: "what the speaker wants to say with an expression is connected both with what is literally said in it and with the action as which it should be understood" (p. 315). Hence, this philosophical lens seems to be suitable for analysing the decision-making processes of the teacher through the interplay among the different types of rationality.

However, several philosophers and social theorists have highlighted that, in the development of his theory, Habermas did not take into account the emotional side of human beings. For example, Rienstra and Hook (2006), quoting the philosopher Heller, asserted that "Habermas leaves no room for 'sensuous experiences of hope and despair, of venture and humiliation', accusing him of completely avoiding the 
'creature-like' aspects of human beings" (p. 13). Moreover, Steinhoff stressed that not only will argumentation be used to obtain consensus from the interlocutor about the statements, but all sorts of non-verbal means also play a significant role in the discursive activity. In particular, Steinhoff (2009) affirms that when people conduct discourses "they do try to convince the listener (and for this purpose not all listeners have to be participants in the discourse), but not just with arguments; they also use emotion, rhetoric and all means of achieving strategic influence, and the conflict resolution that discourse might be aimed at does not have to be consensual either (why not, for example, through majority decision?)" (p. 147). Summarizing, emotions are connected to reasoning at every moment, in discerning what is true and what is not and providing justifications of what we are stating.

Putting together Habermas' ideas and the critical debates of them, I posited that affective factors are entwined with those of rationality in the decision-making processes of the mathematics teacher. Hence, the original research aim was enlarged, becoming a study of the intertwinement between the emotional and rational aspects in the decision-making processes of a mathematics teacher. There is a need for theoretical frameworks for articulating how these affective factors might be involved in decision-making.

Research in mathematics education has progressively extended to perceive the existence of a mutual interaction between the affective sphere and cognition in mathematics learning (Zan, Brown, Evans, \& Hannula, 2006). But it was in the field of human neuropsychology that I found the most helpful ideas on the relationship between the affective and the rational sphere, starting with the work of Damasio (1994, 1999). Moreover, while educational research often treated decision-making, reasoning, and processes related to reading, language, and mathematics as detached from emotion and body, Immordino-Yang and Damasio (2007) have shown that "learning, in the complex sense in which it happens in schools or the real world, is not a rational or disembodied process; neither is it a lonely one" (p. 4). For them, emotion is "a basic form of decision making, a repertoire of know-how and actions that allows people to respond appropriately in different situations" (p. 7). This neurological research is also becoming applicable in the field of mathematics education. For example, Brown and Reid (2006) have developed and adapted the hypothesis of somatic markers (Damasio, 1994) for studying the decision-making processes.

Brown and Reid (2006) proposed a theoretical framework grounded on the notion of emotional orientation in order to study the decision-making processes of both the teacher and the students. Their study is significant for my research because of its interest in that particular emotional aspect of human behaviour, which Brown and Reid felt to be neglected, and which they saw as "related to the decision-making that happens before conscious awareness of the decision to be made occurs" (p. 179). Hence, the concept "emotional orientation" allows me to speak of the interconnection between rationality and emotion. In fact, as the words themselves suggest, the "orientation" in a teacher's decision-making processes is "emotional", that is, affected by emotions in a certain way. In fact, the authors refer to the notion of emotional orientation as "the criteria for acceptance of an explanation by members of a community" (p. 181) and they consider emotions to be the foundation of such criteria. 
So the criteria, namely the decisions that for example a teacher takes within the classroom are affected by emotions. To better explain this point, they also recall the somatic markers hypothesis of Damasio (1994), proposing to consider somatic markers proper as a basis for mathematical emotional orientations. Somatic markers are structures that inform our actions and decision-making, pushing us to decide something because "It feels right" in terms of its acceptance in a community. So, emotions related to being right are attached to somatic markers, sets of which constitute emotional orientations. In decision-making, "many possibilities are rejected because they are associated with negative somatic markers" (p. 180), while positive somatic markers imply possible behaviours, being revealed by the decisions of the teacher in the activity. If emotional orientation refers to criteria (decisions) to accept an explanation and if at the basis of the choice of such a criterion there are emotions, then we can see emotional orientation as an aspect linked to emotions when choosing certain criteria (decisions) and not others.

For operationalizing the notion of emotional orientation of a teacher, we need an adaptation in terms of her "set of expectations": the term "expectation" is connected to her "emotions of being right" when she uses specific criteria for accepting an explanation by the class rather than other ones (Ferrara \& De Simone, 2014).

Summarizing, I will investigate the intertwinement of rationality and emotions in the teacher's decision-making processes, drawing on this adaptation of the notion of emotional orientation, analysing the decisions a teacher makes in the classroom through the interplay among the different types of rationality à la Habermas.

My research questions are twofold: how does the use of emotional orientation help us understand the decisions of teachers, and thus complement the Habermasian rationality framework and how might it help us understand why teachers make certain choices in their teaching and not others?

\subsection{Methodology}

This study utilizes data from my doctoral thesis (De Simone, 2015), which involved three teachers and their grade nine classrooms. The students were 14 years old and they studied in a scientifically oriented secondary school in Italy. In particular, I chose to focus on lessons on linear equations because this topic is a crucial component of the Italian national curriculum for high school. It is one of the first mathematical content areas in which the delicate "shift" is made from the arithmetical world to the algebraic one. In this chapter, I will concentrate on one of the teachers, Carla, who has completed a master degree for training other teachers.

Carla was first a priori interviewed about the topic of linear equations. The interview was twenty minutes long and was videotaped with the camera facing the interviewer and the subject. The interviews were transcribed for the analysis. Thereafter, five of her lessons were also videotaped. The teacher utterances and bodily actions were transcribed for data analysis. 


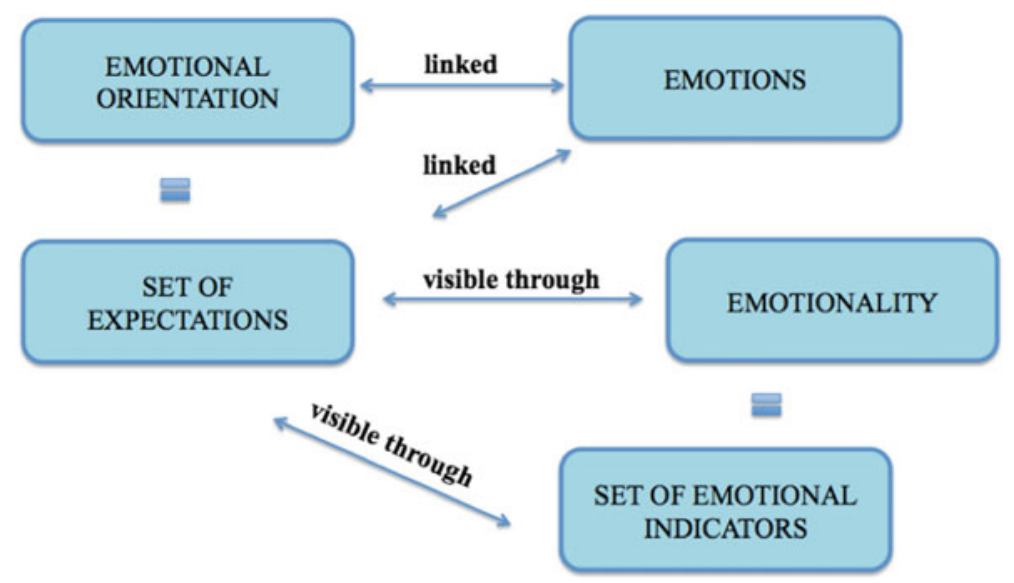

Fig. 11.1 The analytical framework

Concerning the structure of the analysis, I first considered the a priori interview. From what Carla explicitly described to me, I was able to identify some of her expectations with respect to her students. At this stage these expectations were just potential, because it could be that they would not actually drive the actions of the teacher in class. Hence, I also looked at what actually happened in the classroom in order to see if there was a correspondence between what the teacher stated $a$ priori and how she actually behaved in the classroom. For determining whether the expectations were actually reflected in the classroom activity, I looked at the "emotional indicators". In other words, for determining the expectations which the teacher actually reflected in the classroom activities, I observed the gestures, the facial expressions, the emphasis of the words, the repetition, the rhetorical questions, the pauses, the tone of voice, and so on. For example, if a teacher had a very insistent rhythm of words in asking examples, then she actually had the expectation that students would be able to make examples. The emotional indicators informed me about the emotionality of the teachers, where the term emotionality comes from the Penguin Dictionary of Psychology in which it is defined "in terms of behaviours that are observable and theoretically linked to the (hypothetical) underlying emotion..." (Reber et al., 1995). Hence, the expectations of Carla were visible through her emotionality (see Fig. 11.1).

Then, I examined the lessons more carefully in order to identify the intertwinement between the rationality and the emotionality. In particular, I looked at Carla's decisions through the three components of rationality (epistemic, teleological, and communicative) and, looking simultaneously at the emotional indicators and expressions of their expectations, I was able to say something about why she made those decisions and not others.

The emotionality of Carla was revealed by her prosody, her gestures, her facial expressions, her postures, and so on. As her emotionality was found to be always intertwined with her rationality, the teacher emotionality can be interpreted in terms of the Habermasian rationality; as epistemic emotionality, teleological emotionality, and communicative emotionality. 
For example, the epistemic emotionality surfaced when Carla decided to draw on the concept of identity she had already introduced previously and, remaining in a waiting posture, she nodded after confirming that students actually remembered it. Thus, it was not just the kind of knowledge she chose to consider (epistemic rationality), but why she decided to draw on that particular knowledge. The reason is connected to her expectation that the previous knowledge was valid for students and this expectation was made visible through the posture of waiting for something and her nodding after the confirming response by the students.

The teleological emotionality could be highlighted when Carla justified the meaning of solving a linear equation and, at the same time, her voice had the highest pitch corresponding to the word "sense". It was not just the action the teacher made to accomplish a goal, namely justifying the resolution of a linear equation for finding the solution, but also the fact that she had the expectation that the justifications serve to give meaning to what the students are doing. This expectation was made visible through the high pitch of her voice.

The communicative emotionality surfaced when Carla had an insistent rhythm of voice when asking examples. Then, it was not just a matter of the words oriented toward reaching understanding, but also why she decided to communicate with an insistent rhythm. The reason was connected to her expectation that students would be able to make examples and the expectation became clear through the insistent rhythm. Overall, I considered the epistemic emotionality as related to why the teacher used that specific justification of the knowledge at play, the teleological emotionality as related to why the teacher made that action to achieve a goal, and the communicative emotionality as related to why the teacher used that speech oriented towards reaching understanding within the classroom. For pragmatic necessities of analysis, these three types of emotionality could appear to be separated. Nevertheless, it is important to stress that they were always intertwined and present in the discursive activity of the teacher.

\subsection{Data Analysis}

For the topic of equations, Carla started with the definition of an open statement as a logic proposition in which the truth value is determined by the value of one or more independent variables. The open statement contains at least one variable, the value of which is selected within a referring universe set (e.g. $\boldsymbol{U}$ ). The open statement is indicated by a capital letter of the alphabet (e.g. $\boldsymbol{P}$ ) and the variable is indicated in brackets by a lower case letter of the alphabet (e.g. $\boldsymbol{x})$. The open statement $\boldsymbol{P}(\boldsymbol{x})$ can be true or false with respect to the value assumed by the variable $\boldsymbol{x}$, chosen within the universe set $\boldsymbol{U}$. For example, given the universe set $\boldsymbol{U}=\{\boldsymbol{x} \in \boldsymbol{N}: \boldsymbol{x} \leq 20\}$ the open statement $(\boldsymbol{x}): \boldsymbol{x}$ is even, is true for $\{2,4,6,8,10,12,14,16,18,20\}$ and false for the others.

Carla explained what an open statement is in order to show linear equations as open statements in which the verb is "being equal to". This open statement can be 
true for one value ascribed to the variable (determined equation), it can be false for each value of the variable (impossible equation), or it can be true for all the values substituted to the variable (indeterminate equation).

The following passage comes from the a priori interview of Carla in which she spoke about her conception of the role of the previous knowledge of students:

The greatest problem I'm trying to solve - I realised and it's becoming dramatic in the last years - is the problem of the stability of knowledge, in that I feel that in many classrooms, except the good ones, students don't remember what we did and, for me, this is serious. That is, for example, in grade ten, I would like to refer to something that I did before, on which I have even insisted, without having to repeat it entirely (...) the big problem to solve, in that I persist a lot, is being able to find a way for constructing a core (miming a base with her hand), a base of knowledge (miming a list with her open hand), of abilities that stay. For me, aside from time economy -'cause, maybe, it's a bit annoying having always to recall it's really a matter that has to do with cognitive science, I don't know, I wouldn't know how to face it, but it's becoming a general problem, then we should look for (...) the problem is looking for meaningful activities that allow (...) fixing things.

As showed in this brief piece above, for Carla, classroom culture was very important for having knowledge stability. Hence, from what she declared, I identified her expectation of constructing new knowledge from what has been already done in the classroom.

The expectation determined choices, for example, as the next excerpt of Carla's lessons will show (Table 11.1). She recalled the definition of "open statement", for constructing that of equation, as a particular open statement with the verb "to be equal to":

Table 11.1 First excerpt of Carla's classroom activity

1. $\mathrm{T}$ : then, we considered open statements. In general, what is an open statement? [pause, gesture as in Fig. 11.2]

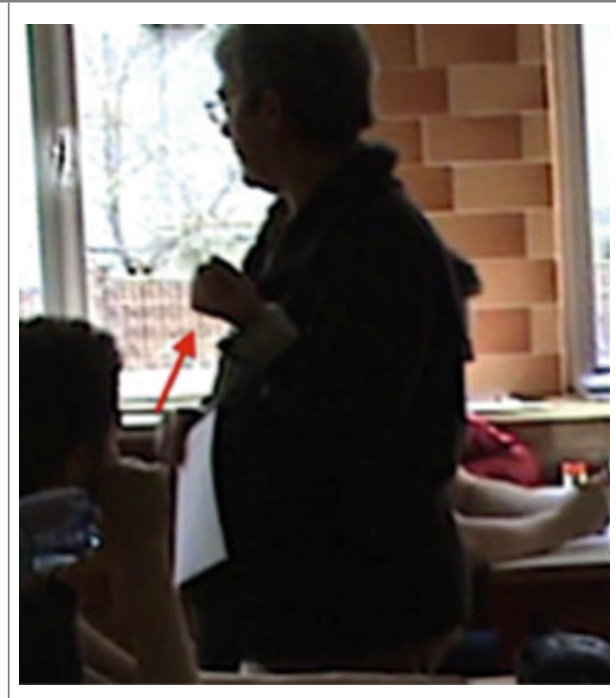

Fig. 11.2 Carla's gesture

2. S10: a proposition that

(continued) 
Table 11.1 (continued)

3. $\mathrm{T}$ : it is a phrase where a variable appears for which, first of all, we have to define [pause and waiting,

Fig. 11.3] what is the universe set, right? Try to answer to the questions I make in order to [Fig. 11.4] summarize. For an open statement, can we say if it is true or false?

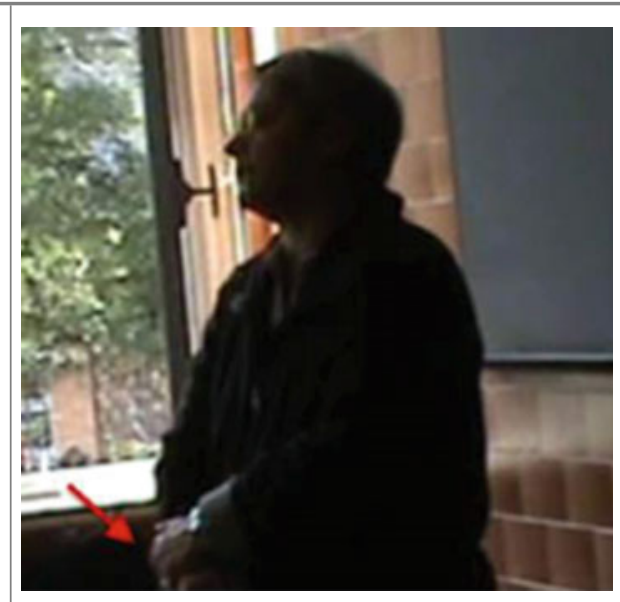

Fig. 11.3 Carla pauses with her hands gathered together

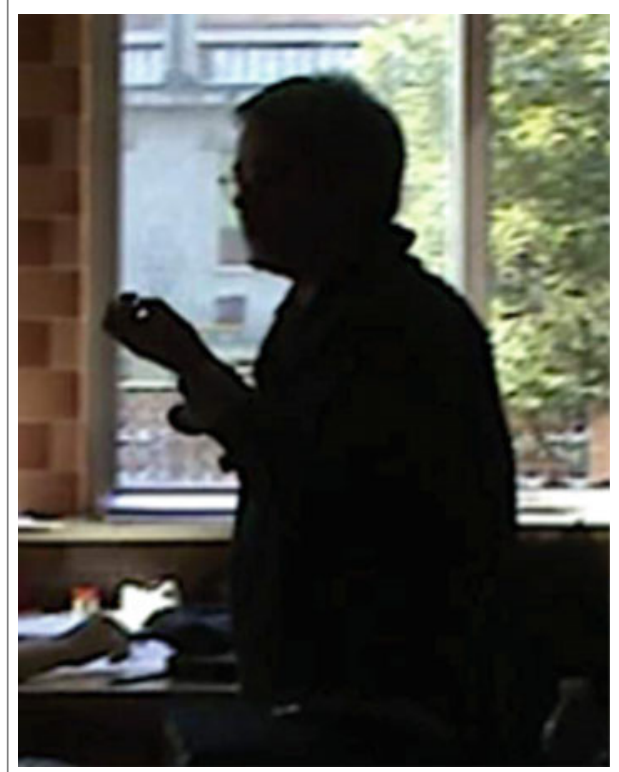

Fig. 11.4 Carla's gesture that conveys the meaning of summarizing

4. Ss: no, we can't say

5. S19: what is the truth set

6. T: [nodding] in general, what do we call the truth set? 
Table 11.1 (continued)

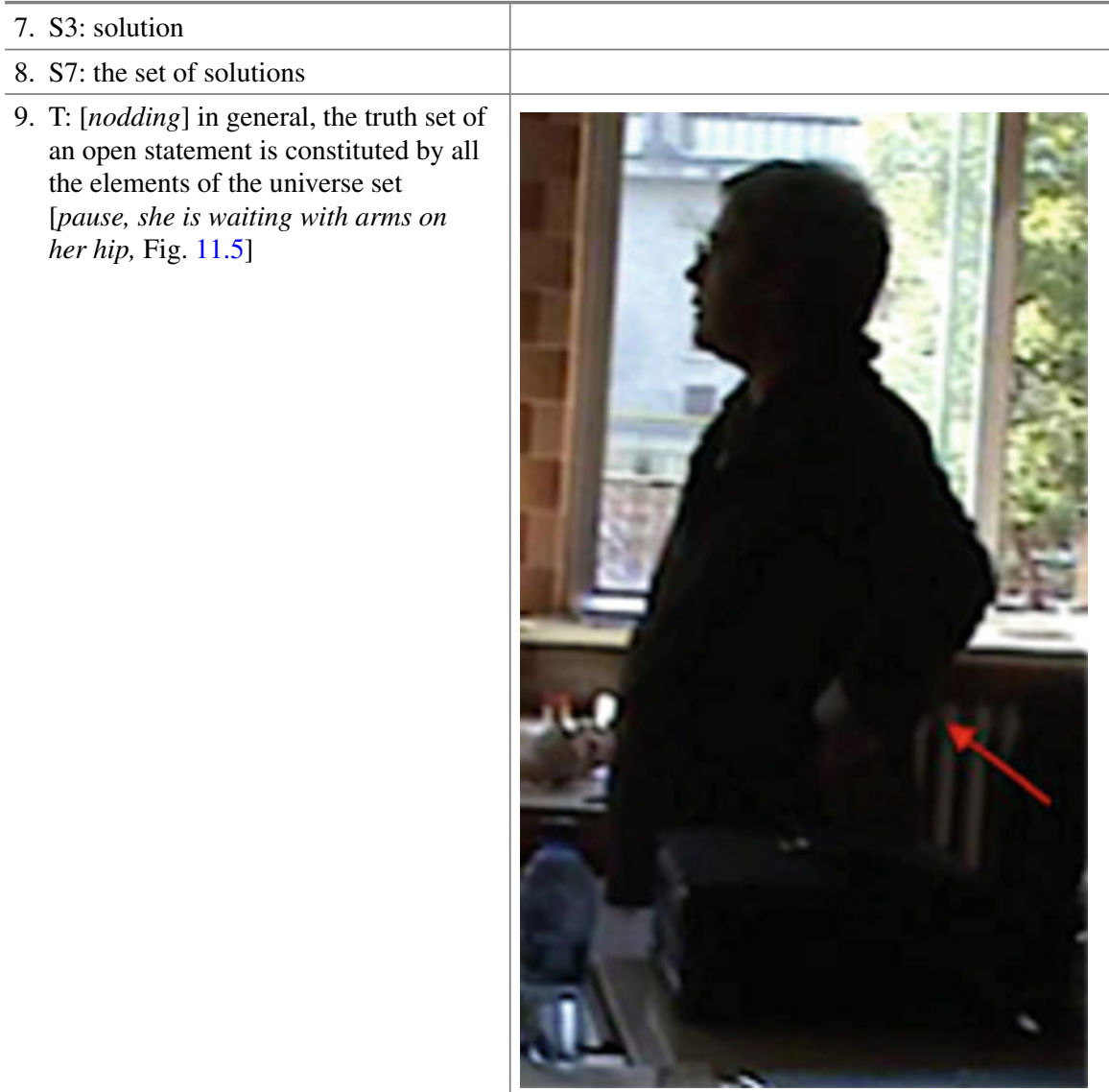

Fig. 11.5 Carla's posture of waiting for an answer from her class

10. S5: that makes true the statement

11. T: that makes it true, then the equations-and this fact had to emerge here-are particular open statements in which the predicate is "to be equal to". Then, as for all the open statements, of an equation [raising her eyebrows], obviously given the universe set, we ask ourselves what is the truth set, that for tradition it is called the set of solutions, and an element of it, it is called a solution. 
Carla focused students' attention on how they have already defined an "open statement". Indeed, she wanted to introduce the concept of equation as an open statement with the predicate "to be equal to". For this reason, she explicitly asked her students what an open statement is. She accompanied this request with the gesture in Fig. 11.2, through which she seemed to hope to have the classroom in her control. Then, she wanted to remind the students of the importance of saying what the referring universe set is. She was waiting for an answer from students as shown in Fig. 11.3 (\#3). She expected someone to say something, because, in the previous part of the lesson, she stressed that for an open statement it is important to specify the universe set. In fact, the statement's truth value depends on the set in which it is defined. At the end, she answered herself with a rhetorical question ("what is the universe set, right?" \#3). Then, she continued, because, probably, she felt confident that the students were aware of this fact. Indeed, the discussion continued and Carla with her students considered what the truth set of an open statement was. Later she was expecting, probably a little irritated (Fig. 11.5: \#9), that students would remember its definition.

Carla's epistemic emotionality was constituted by the knowledge of the concept of an open statement, by the important role of the universe set (rational key), and by her hope that students had already learned the definition of an open statement (emotional key). In particular, she was waiting for a relevant feedback from her students because she had already explained open statements and, probably, she felt that she had been effective in doing that. This emotional key was disclosed, for example, by the gesture in Fig. 11.4; by the posture of waiting for students' response as shown in Fig. 11.5; by the rhetorical question ("what is the universe set, right?") through which it is clear that this knowledge had been already introduced. In fact, it was not necessary to explain it again, but just recalling it with a rhetorical intonation. Carla's teleological emotionality concerned both the recalling what they have already discussed about open statements in order to speak of equations (rational key) and her expectation that it would be sufficient to just review open statements, because she was expecting that students remember them (emotional key). This emotional key was disclosed by the verb "summarize" that comes along with the gesture in Fig. 11.4. This could be seen as a hint of her expectation about the validity of the previous knowledge: it was already known by the students, hence now it was important to answer her questions just to summarize the previous knowledge. As a human being, she could not detach her body from her speech, hence her discourse was full of emotional elements. In particular her speech was accompanied by postures, gestures, and rhetorical intonation which together contributed to her communicative emotionality.

Moreover, in the passage below (Table 11.2), Carla constructs the "properties of linear equations" by referring back to the "law of monotonies ${ }^{1}$ " for equalities that were explained at the start of the year. As will be shown in the next section, students were able to construct this mathematical content themselves, by drawing on their previous knowledge.

\footnotetext{
${ }^{1}$ They are laws related to the substitution property, according to which adding/subtracting the same number to, or multiplying/dividing by it, both sides of an equality does not change the equality.
} 
Table 11.2 Second excerpt of Carla's classroom activity

1. T: Instead [highest pitch] for the
second "law of monotony" [nodding,
she stops in speaking, she bites her
lips and she closes her fist: Fig. 11.6]?

In this brief passage, the teacher was speaking of the second monotony law (\#1). When students constructed that knowledge, she remained - for the whole time-in the same attitude that was constituted by her closed fist, her nodding and tightening her lips (\#1, \#2, \#3, \#4, \#5: Fig. 11.6). Hence, there was an epistemic emotionality from Carla that was not only the knowledge of the "laws of monotony" for equalities (rational key), but also the fact that Carla hoped for her students to remember what they had already done with equalities. This way they could see the analogy to equations, given that she was expecting students to consider equations as open statements of equalities (emotional key). This emotional key was shown, for example, by her emblematic attitude indicated, for example, by her pauses and her nodding 
(Fig. 11.6) when the students, one after the other, jointly constructed the principles of equivalence in \#2, \#3, \#4, \#5. The teacher was engaged in the discursive activity with the class not only from a rational point of view, but also from an emotional point of view: she has hopes, expectations, and also needs. Both these sides were reflected in her speech because a teacher cannot be purely rational only in her discourse. Hence, I speak of the communicative emotionality of Carla. It was disclosed by her posture, her gestures, her stopping in speaking, and the tightening of her lips. This information allows me to say something about why she decided to act in a certain way.

In the a priori interview, Carla spoke of the role of justification in her teaching activity, as can be seen in the following excerpts:

(gesture with joined fingers and she beats on the table) I insist very much on why the letters instead of numbers [...] It is always a discourse to give sense, a meaning to what we are doing.

I always justify the use of letters, I anticipated it a lot, for example when we speak of problems I say that, through letters, we can solve a class of problems, instead of solving a single numerical problem [...] When I treat the resolution of equations, I am very careful of the conscious use of the properties of equations. I'm worried that it is not a mechanical thing.

As shown above, justification was very significant for Carla and, for this reason, I infer that she had an expectation that the justifications are necessary to give sense to what she and her students do.

Moreover, Carla was not just concerned with giving justifications during her classroom activity, but, as can be seen below, she expected that justifying would become an ordinary practice also for the students, in order to give a sense to what they are doing:

(self-confident tone of voice) ah yes, sure, I ask always "let's justify your reasoning" (she begins to gesture), "let's justify your answer", yes, sure, both during the work within the classroom and in the exams in class" [...] (Carla spoke about the national assessment for the middle school). For me, something is evolving in middle school. Many people say that this assessment "falls on the head", but it serves to give meaning to what is being done. Many tasks in this assessment have the question "Explain why", and then students have to expose and justify their reasoning [...]. I make many tests of the type "know" and "know-how"; the "know" is the set of justifications that students give in relation to what they do. Concerning equations, for example, I gave a problem of the type "given an equation, write an equivalent one to it applying just the first principle of equivalence and explain why".

As anticipated above, the teacher not only gave reasons to what she does herself, but, at the same time, she also had the expectation that also her students would feel the need to justify to give sense to what they do.

I found these two expectations on the role of justification contributing to the shaping of Carla's emotional orientation, which was reflected many times during her classroom activity. For example, in the specific passage of her lessons that I'm going to show, Carla gave many equations to her students to solve and she explicitly declared that in order to solve them, they "have to give a meaning to what you read". In different moments, Carla posed her students questions like "How do you justify your answer?", or "Let's justify your answer" (Table 11.3). 
Table 11.3 Third excerpt of Carla's classroom activity

1. $\mathrm{T}$ : There were equations in which you had to find the truth set, treating them as they are, that is as open statements, without making particular calculation, but trying to see which elements make the statement true. Then, in $(x+1)^{2}=81$ and $U=Z$, what did you find?

2. S5: 8; S9:-10; Ss: -9

3. T: the unique way for seeing who is right is trying to substitute. Try to substitute, then pay attention, I have told you that this has to be always kept in mind, that you have to give a [she makes a punctual gesture for stressing the next word "sense" [Fig. 11.7 and pronounces it in the highest pitch] sense of what you read. Then, solving the equation $(x+1)^{2}=81$ means asking if there exists a value $x$ such that doing $x+1$ and squaring it, we obtain 81 , working in [highest pitch and raising eyebrows] $Z$, this should make sense to you that [Fig. 11.8, indicating $x+1$ with fingers $] x+1$, [she inclines her body towards the class] how it has to be?

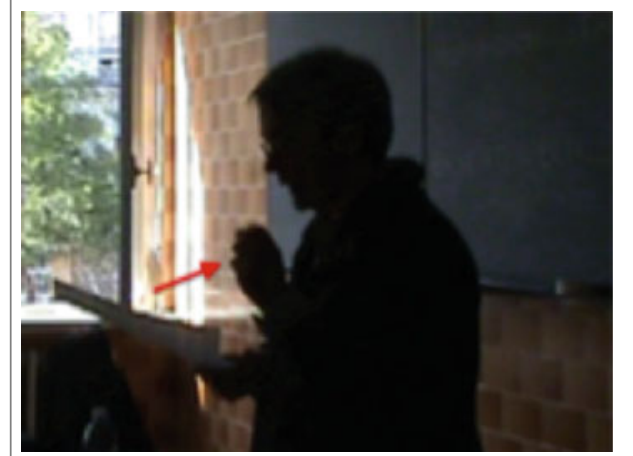

Fig. 11.7 Carla's gesture for stressing the word "sense"

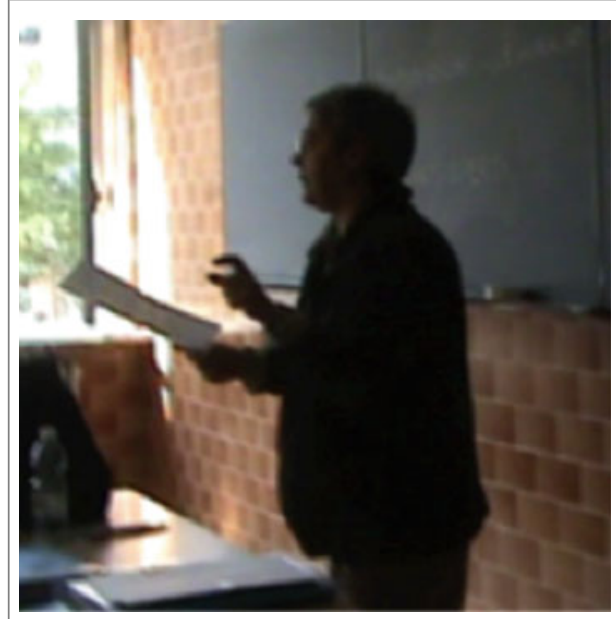

Fig. 11.8 Carla's gesture for referring to a part of the considered equation 
Table 11.3 (continued)

4. Ss: 9 or -9

5. T: How $x+1$ has to be? If it's squared must be [she inclines her body towards the class, Fig. 11.9] 81? $x+1$ must be equal to 9 or -9 because of [pronouncing and raising eyebrows, Fig. 11.10] integers whose square is 81 there is not only 9 but also -9 and then what are the elements?

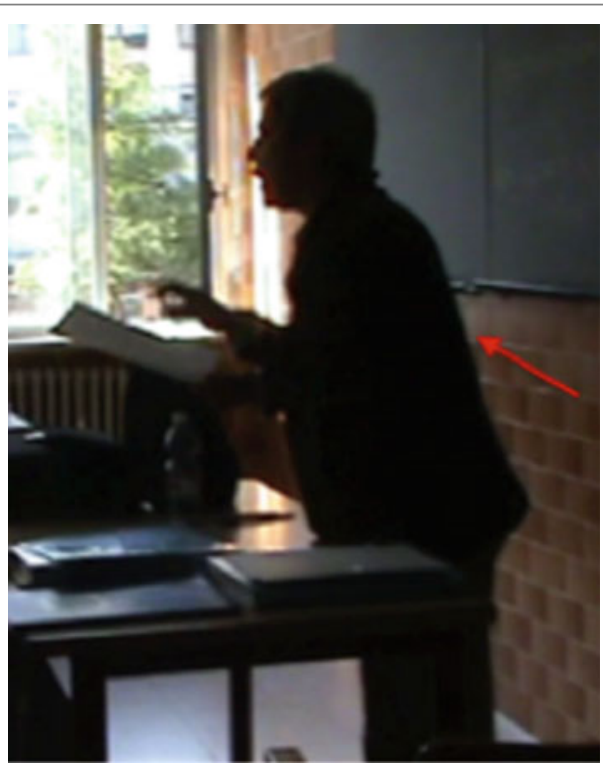

Fig. 11.9 Carla's posture for involving the whole class in the discussion

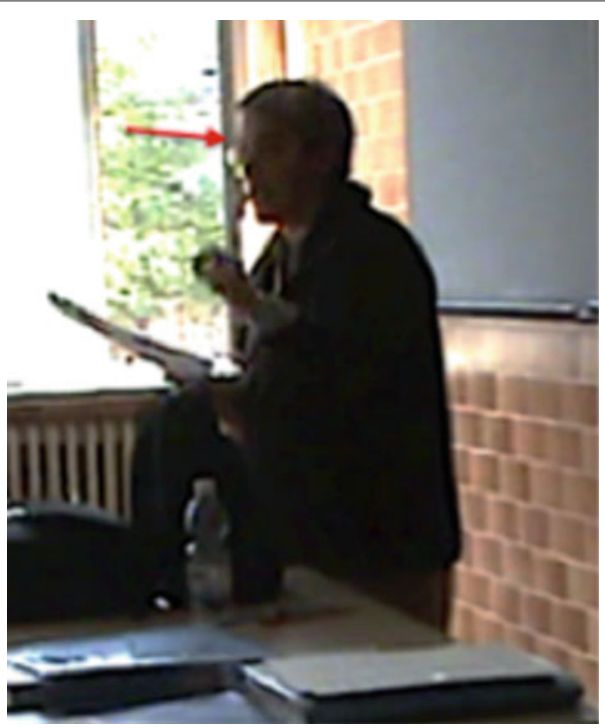

Fig. 11.10 Carla's facial expression

6. Ss: 8 and -10

7. $\mathrm{T}: 8$ and -10 [nodding], and in $(x+5)(x-2)=0, U=Z$, what have you found? 
Table 11.3 (continued)

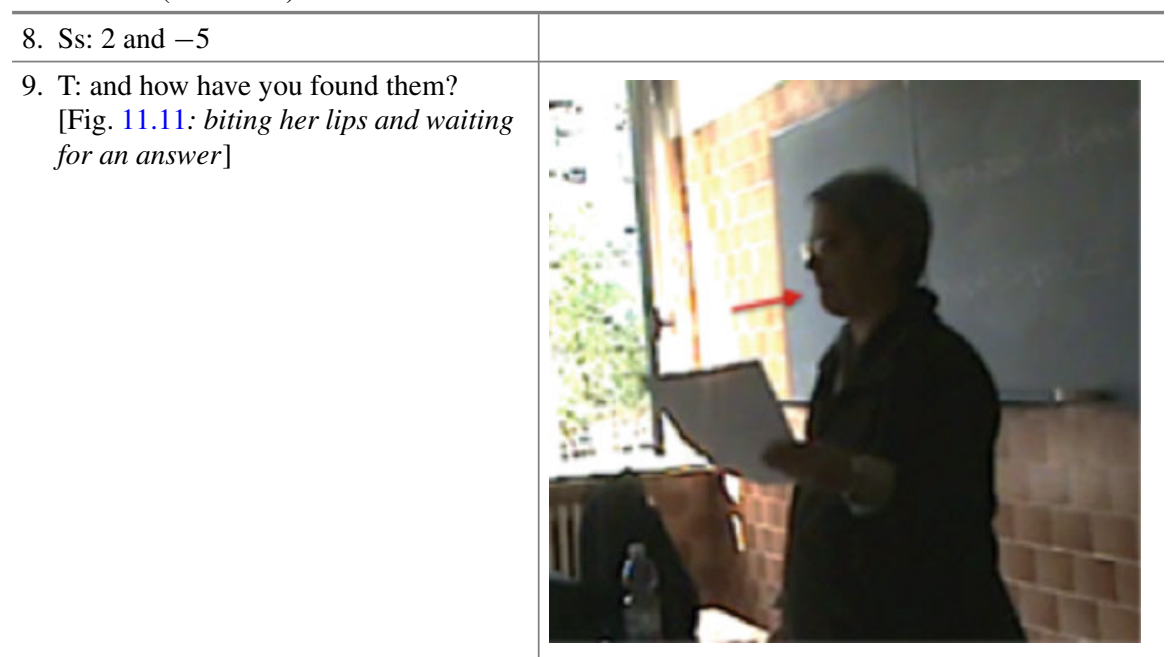

Fig. 11.11 Carla's facial expression when she is waiting for an answer

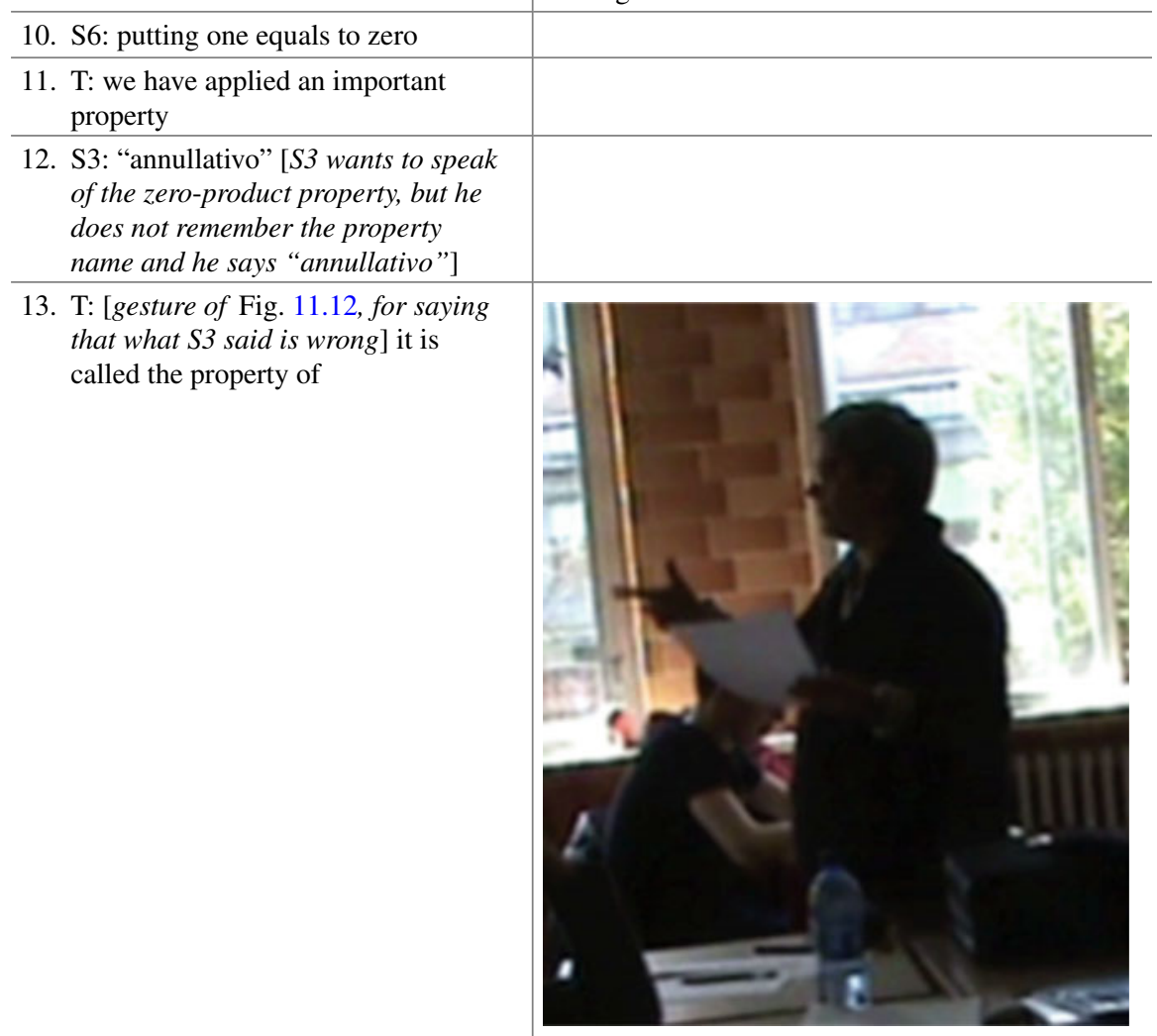

Fig. 11.12 Carla's gesture pointing a student (continued) 
Table 11.3 (continued)

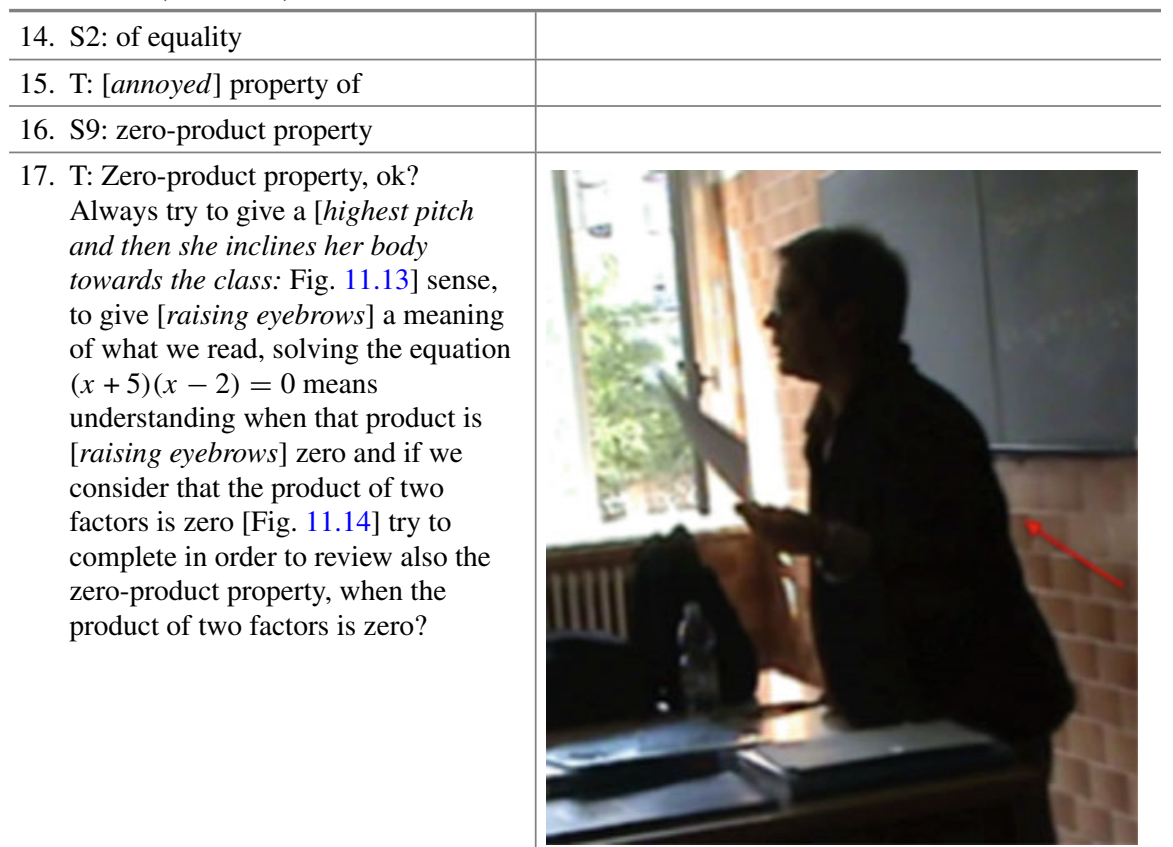

Fig. 11.13 Carla's posture for involving the whole class in the discussion

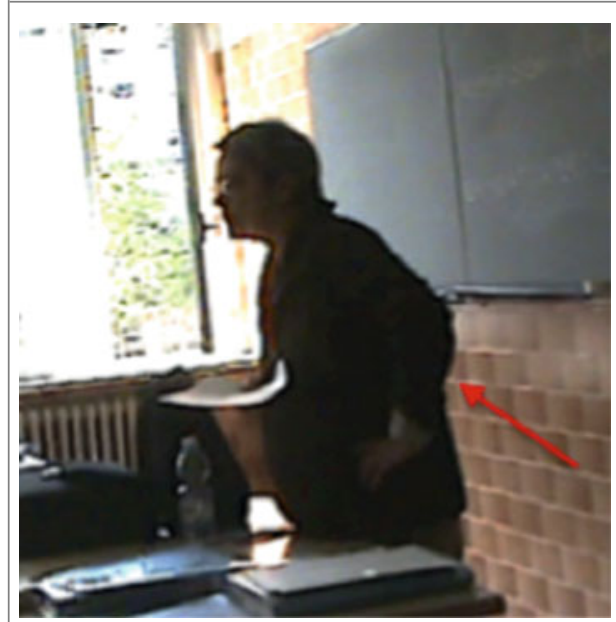

Fig. 11.14 Carla's posture

18. Ss: when one of them is zero

19. $\mathrm{T}$ : [nodding and raising eyebrows] when at least one of them is zero and [pause] vice versa 
Carla discussed with her class an activity in which students had to find the solution set with respect to the assigned universe set. She was very careful in justifying what she did and she required the same attitude from the students. For example, in the case of the equation $(\boldsymbol{x}+1)^{2}=81$, in $\boldsymbol{U}=\boldsymbol{Z}$, there were different opinions among students (\#2). Hence, Carla invited them to substitute the number for the unknown in order to verify who was right (\#3). She explicitly explained what is the meaning of solving the equation $(x+1)^{2}=81$ and she stressed that students had to always keep in mind the sense of what they read or did (\#3). This statement was accompanied by a particular facial expression and a gesture (Fig. 11.7) for emphasizing what she was saying, by her inclining her body towards the class and pronouncing the word "sense" in a higher pitch and with eyebrows raised (\#3). Returning to the example, she repeated what students already said, that is, the solutions of the equation in $\mathrm{Z}$ are 9 or -9 . She stressed why these are the solutions: because 9 and -9 are the only integers whose square is 81 (\#5). This justification came along with her inclining her body towards the class as in Fig. 11.9 and stressing of the word "integers", raising eyebrows again (Fig. 11.10). In the justification of another equation, $(x+5)(x-2)=0$ in $\boldsymbol{Z}$, she explicitly asked students how they had found that solution, expecting an answer, biting her lips as in Fig. 11.11 (\#9). Moreover, when she wanted to justify the resolution of one equation with the zero-product property and the students did not remember it, she seemed annoyed (\#13, \#15). Furthermore, she required the students to recall the zero-product property in order to understand the justification of the resolution of that equation (\#17: In Figs. 11.13 and 11.14 she inclined her body towards the class to encourage a response from the students).

Hence, it is possible to outline the three different natures of the intertwined rationality and emotionality of the teacher. The epistemic emotionality was constituted both by the resolution of a quadratic equation (rational key) and by the fact that she was expecting that students feel the need for justification (emotional key). This emotional key was shown, for example, by her raising her eyebrows and inclining her body towards the class corresponding to a request of justification from the students, and by her biting the lips for waiting for the justification from the students. She was expecting the same behaviour from students also when they did not justify correctly what they had done with an equation. In fact, she seemed very annoyed after the wrong answer (\#15) and she was waiting for them to recall the zero-product property in Fig. 11.14 (\#17). Her teleological component was prompted by the fact that Carla wanted to justify all the solutions of the equation (rational key), but she went further, because she was hoping for the justifications to be giving a sense for what they were doing (emotional key, revealed by her facial expression in Fig. 11.13, and by the pronouncing the term "sense" in a high pitch \#17). Moreover, the teacher's teleological emotionality was seen in a meta-level teleological component that went beyond just clarifying what students were doing. In general, her speech, being emotionally involved, couldn't be neutral and for this reason there were two different aspects in her discourse: from one side there is what she was saying, but, from the other one, there were all the different aspects (gestures, prosody...) that showed her emotional engagement in the discussion. Hence, the teacher had also communicative emotionality. 


\subsection{Discussion and Conclusion}

As shown in the data analysis, I have been able to better understand Carla's decisions through the concept of emotional orientation, operationalized as the set of her expectations. In particular, by identifying the epistemic, the teleological, and the communicative emotionalities, I was able to explain why she decided to put into play that specific knowledge related to equations; why she acted in a specific way for achieving a particular goal; why she spoke in a particular manner within the classroom when she was trying to help her students understand. With the pure rationality à la Habermas, I could have only described the decisions of the teacher, without accounting for their underlying reasons. In this sense, complementing the Habermasian rationality with the affective dimension has given an added value, allowing me to explain the reasons for the teacher's moment-to-moment decisions.

In my doctoral thesis (De Simone, 2015), I analysed many others parts of Carla's lectures, in which her expectations about the stability of the knowledge of the students and about the role of the justification were present. The interesting thing is that these expectations were always visible through the same the emotional indicators (e.g., prosody, facial expressions, and gestures). Hence, it is reasonable to outline a "model" for Carla. For example, Carla recalled previous knowledge when she introduced the definition of a new mathematical concept, for example that of linear equation. Hence, concerning her expectation about the stability of the previous knowledge, she employed the same emotional indicators. In particular, she increased the tone of voice, she pronounced, and she specified with gestures what she wanted her students to recall. Hence, it seems quite clear that she expected her students to have understood the importance of what they have already learned. In addition, she invited students to recall it shortly before the introduction of a new topic, raising eyebrows and gesturing to encourage them to draw on previous knowledge. In particular, she appeared quite irritated when students did not react to her suggestions. Then, her hope that students would remember previous knowledge in order to construct new knowledge by drawing on previously learnt material became visible. In short, she seemed "to pass on" the need of justifying and, simultaneously, she hoped that she was effective in doing it.

Moving on to the role that Carla gave to justification, she showed almost the same emotional indicators. For example, she articulated with emphasis and she increased the tone of voice for what she wanted to justify, she raised her eyebrows and she inclined her body towards the class. Probably, she hoped that her students would understand that she was highlighting the need to justify in order to give sense to what they do. In addition, it appeared quite clear that she expected the same approach from students; in fact, she always inclined towards them as if "to transfer" this need for justification. In particular, she expressed her insistence that students should give a meaning to what they do, waiting for justifications, and being quite irritated when they avoided them.

Summarizing, the activity of the teacher, Carla, was the combined result of both the rational component constituted by her decisions and the emotional component 
constituted by what she was feeling in that precise moment. The latter cannot be prepared a priori. The emotions were triggered by the expectations that Carla had for her teaching. I will use the metaphor of the actor in order to better capture this situation. The actor knows how the story he plays will finish. Hence, the actor is prepared a priori and, when he is playing the story, he has to communicate this to the audience. In the case of the teacher, she also knows where she wants to go, but, unlike the actor, she does not know a priori if she will obtain it, because it depends on how the students react. This fact produces expectations in the teacher and, then, she employs all of her means to reach her aim. The teacher establishes a communicative channel with students in order to have answers of a certain type from them.

Hence, the rationality and the emotionality of the teacher are not separable but coexist in the complex activity of the subject. I do not mean that emotion rules rationality. The teacher does not base her teaching just on her sensibility, nor just on her passion. It is the combination of the rational and emotional sides that will allow her to obtain efficient results.

\section{References}

Bishop, A. J. (1976). Decision-making, the intervening variable. Educational Studies in Mathematics, 7(1-2), 41-47.

Boero, P., Douek, N., Morselli, F., \& Pedemonte, B. (2010). Argumentation and proof: A contribution to theoretical perspectives and their classroom implementation. In Proceedings of the 34th PME Conference (Vol. 1, pp. 179-204). Belo Horizonte, Brazil: PME.

Boero, P., \& Planas, N. (2014). Habermas' construct of rational behavior in mathematics education: New advances and research questions. In P. Liljedahl, C. Nicol, S. Oesterle, D. Allan (Eds.), Proceedings of the 38th PME and PME-NA Conference (Vol.1, pp. 205-235). Vancouver, Canada: PME.

Brown, L., \& Reid, D. A. (2006). Embodied cognition: Somatic markers, purposes and emotional orientations. Educational Studies in Mathematics, 63(2), 179-192.

Damasio, A. (1994). Descartes' error. New York, NY: Avon Books.

Damasio, A. (1999). The feeling of what happens: Body and emotion in the making of consciousness. San Diego, CA: Harcourt.

De Simone, M. (2015). Rationality in mathematics teaching: The emergence of emotions in decisionmaking (Doctoral dissertation). Dipartimento di Matematica "Giuseppe Peano", Torino, Italy. https://iris.unito.it/handle/2318/1509078?mode=full.300\#.W5YvHlcYHUo.

Ferrara, F., \& De Simone, M. (2014). Using Habermas in the study of mathematics teaching: The need for a wider perspective. In P. Liljedahl, C. Nicol, S. Oesterle, D. Allan (Eds.), Proceedings of the 38th PME and PME-NA Conference (Vol. 1, pp. 223-228). Vancouver, Canada: PME.

Habermas, J. (1998). On the pragmatics of communication. Cambridge, MA: MIT Press.

Immordino-Yang, M. H., \& Damasio, A. (2007). We feel, therefore we learn: The relevance of affective and social neuroscience to education. Mind, Brain, and Education, 1(1), 3-10.

Reber, A. S., Allen, R., \& Reber, E. S. (1995). The Penguin dictionary of psychology. New York, NY: Penguin Press.

Rienstra, B., \& Hook, D. (2006). Weakening habermas: The undoing of communicative rationality. Politikon, 33(3), 313-339.

Steinhoff, U. (2009). The philosophy of Jürgen Habermas: A critical introduction. Oxford, UK: Oxford University Press. 
Zan, R., Brown, L., Evans, J., \& Hannula, M. (2006). Affect in mathematics education: An introduction. Educational Studies in Mathematics, 63(2), 113-121.

Open Access This chapter is licensed under the terms of the Creative Commons Attribution 4.0 International License (http://creativecommons.org/licenses/by/4.0/), which permits use, sharing, adaptation, distribution and reproduction in any medium or format, as long as you give appropriate credit to the original author(s) and the source, provide a link to the Creative Commons license and indicate if changes were made.

The images or other third party material in this chapter are included in the chapter's Creative Commons license, unless indicated otherwise in a credit line to the material. If material is not included in the chapter's Creative Commons license and your intended use is not permitted by statutory regulation or exceeds the permitted use, you will need to obtain permission directly from the copyright holder.

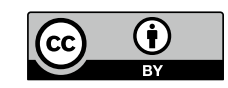

